\title{
Effective Selective Head Cooling during Posthypoxic Hypothermia in Newborn Piglets
}

\author{
MARIANNE THORESEN, MARTIN SIMMONDS, SAULIUS SATAS, JAMES TOOLEY, AND \\ IAN A. SILVER \\ Department of Child Health, St. Michael's Hospital, University of Bristol, Bristol, U.K. [M.T., M.S., S.S., \\ J.T.]; and Department of Anatomy, School of Veterinary Science, University of Bristol, Bristol, U.K
}

[I.A.S.].

\section{ABSTRACT}

\begin{abstract}
Selective head cooling has been proposed as a neuroprotective intervention after hypoxia-ischemia in which the brain is cooled without subjecting the rest of the body to significant hypothermia, thus minimizing adverse systemic effects. There are little data showing it is possible to cool the brain more than the body. We have therefore applied selective head cooling to our hypoxia-ischemia piglet model to establish whether it is possible. Nine piglets were anesthetized, and brain temperature was measured at the surface and in the superficial $(0.2 \mathrm{~cm})$ and deep $(1.7-2.0 \mathrm{~cm})$ gray matter. Rectal $(6-\mathrm{cm}$ depth), skin, and scalp temperatures $(\mathrm{T})$ were recorded continuously. Lowering T-rectal from normothermia $\left(39^{\circ} \mathrm{C}\right)$ to hypothermia $\left(33.5-33.8^{\circ} \mathrm{C}\right)$ using a head cap perfused with cold $\left(6-24^{\circ} \mathrm{C}\right)$ water was undertaken for up to $6 \mathrm{~h}$. To assess the impact of the 45-min hypoxiaischemia insult on the effectiveness of selective head cooling, four piglets were cooled both before and after the insult, and four, only afterward. During selective head cooling, it was
\end{abstract}

possible to achieve a lower T-deep brain than T-rectal in all animals both before and after hypoxia. However, this was only possible when overhead body heating was used. The T-rectal to T-deep brain gradient was significantly smaller after the insult (median, $5.3^{\circ} \mathrm{C}$; range, $4.2-8.5^{\circ} \mathrm{C}$ versus $3.0^{\circ} \mathrm{C} ; 1.7-7.4^{\circ} \mathrm{C} ; p=$ 0.008 ). During rewarming to normothermia, the gradient was maintained at $4.5^{\circ} \mathrm{C}$. We report for the first time a study, which by direct measurement of deep intracerebral temperatures, validates the cooling cap as an effective method of selective brain cooling in a newborn animal hypoxia-ischemia model. (Pediatr Res 49: 594-599, 2001)

HI, hypoxic-ischemic

Abbreviations:

SHC, selective head cooling

T-rectal, rectal temperature

T-deep brain, deep brain temperature
Mild and moderate hypothermia can be neuroprotective after an $\mathrm{HI}$ insult (1-6). Hypothermia is thought to interfere with different damaging cascades, being protective both in itself and in prolonging the window for effective application of other neuroprotective strategies, e.g. antioxidant, antiapoptotic, or antiinflammatory drug treatments. To be clinically useful, hypothermia must be safe. Adverse systemic effects of accidental total body hypothermia in adults and infants include metabolic, cardiovascular, hematologic, and immunologic disturbances $(7,8)$. One study of mild, moderate, or severe hypothermia after cardiac arrest in dogs (9) showed best results with mild hypothermia. The authors suggested this was because of fewer adverse systemic effects. SHC is a method by which it might be possible to cool the brain without subjecting the rest of the body to significant hypothermia. A safety study of SHC after

Received November 15, 2000; accepted December 14, 2000.

Correspondence and reprint requests: Marianne Thoresen, M.D., Ph.D., Department of Child Health, St. Michael's Hospital, level D, Southwell Street, Bristol BS2 8EG, U.K.; e-mail: marianne.thoresen@bristol.ac.uk

Supported by a grant from the Wellcome Trust. perinatal asphyxia reported no adverse systemic effects (10), but the T-rectal in this investigation was only lowered to $35.7-36.3^{\circ} \mathrm{C}$. However, a pilot study of both whole body and head cooling in newborn infants to T-rectal $33.5-34.5^{\circ} \mathrm{C}$ showed periods of cardiovascular instability, although no irreversible adverse outcomes were reported (11).

It has not yet been shown in humans that it is possible to cool the brain more than the body. In adults, a cooling cap perfused with water at $10^{\circ} \mathrm{C}$ failed to decrease the brain temperature even in very superficial regions (12), A study of adult neurosurgical patients achieved only a $1^{\circ} \mathrm{C}$ fall in epidural temperature when a cooling cap was added to total body cooling for $8 \mathrm{~h}$, and the T-rectal and intraventricular temperature were unaffected (13). A recent mathematical model of the human newborn brain predicted that head cooling would not selectively cool the brain beyond $1.7 \mathrm{~cm}$ depth (14). However, Tadler et al. (15) managed to cool the adult pig brain after cardiac arrest by $2^{\circ} \mathrm{C}$ at a depth of $2 \mathrm{~cm}$ by using ice packs on the head. We have previously described a noninvasive newborn piglet model of a global HI insult (16), in which mild total 
body cooling reduces T-rectal and T-deep brain to the same degree (17).

We have now investigated whether the piglet brain can be cooled selectively to a greater extent than the rest of the body, by circulating cold water through a hollow cap around the head, while heating the rest of the body. We also examined the effect of prior hypoxia on the cooling and rewarming characteristics of the brain. These are important problems because in clinical practice it is currently not possible to measure T-deep brain directly in newborn infants whose heads are cooled.

\section{METHODS}

The protocol was conducted under Home Office license in accordance with U.K. guidelines. Nine crossbred Landrace/ Large White piglets of either sex were obtained from an approved farm on the morning of the study. They were maintained and monitored before, during, and after the severe, transient $\mathrm{HI}$ insult in accordance with procedures reported previously (16).

Anesthesia and ventilation. Unrestrained animals were anesthetized with halothane $2.0 \%$ in a closed Perspex box, followed by endotracheal intubation and mechanical ventilation (Neovent 90, Vickers Medical, Sidcup, U.K.) with halothane, nitrous oxide $65 \%$, and oxygen $35 \%$. Ventilation was adjusted to keep end-tidal carbon dioxide at $4.5-5.5 \mathrm{kPa}$. During this time the inspired oxygen fraction was altered to maintain transcutaneous arterial oxygen saturation $\geq 96 \%$ before and after the hypoxic insult (Masimo SET, Masimo Corporation, CA, U.S.A.).

Vascular access and fluids. An ear vein, an umbilical artery, and the umbilical vein were catheterized for repeated blood sampling and the infusion of fluids $(3.75 \%$ dextrose and $0.45 \%$ saline at $7.5 \mathrm{~mL} / \mathrm{kg} / \mathrm{h}$ ).

Cardiac monitoring. Mean arterial blood pressure was recorded from the umbilical artery.

Temperature monitoring. Temperatures were recorded from a rectal probe inserted to $6 \mathrm{~cm}$ from the anal margin and from surface probes on the thigh (designated skin temperature probe) and the scalp (fontanelle temperature probe; 400 series, Yellow Springs Instrument Co, Inc, Yellow Springs, OH, U.S.A.). Brain temperature was measured with two or four sensors, designated as A, B, C, and D (Fig. 1). Needle thermocouple probes A and B (superficial and deep transosseous, respectively) were inserted laterally through the skull into the brain on a horizontal plane running from the upper anterior ear margin to the lateral canthus of the eye with the piglet head in a level, standardized position. The anterior probe (A) was inserted $0.2 \mathrm{~cm}$ into the cerebral cortex, and the posterior probe (B), $1.7 \mathrm{~cm}$ into the deep gray matter fixed to a rigid platform. Thermistor probes C and D (400 series, Yellow Springs Instrument $\mathrm{Co}$, Inc) were embedded into a 1.0 -cm-diameter acrylic disc that was sealed into an artificial lateral fontanelle posterior to the bregma (the newborn piglet has no patent fontanelle). Probe $\mathrm{C}$ was in the epidural space beneath the skull. The tip of probe $\mathrm{D}$ was $2 \mathrm{~cm}$ vertically from the brain surface and $0.5 \mathrm{~cm}$ posterior to the bregma. Each probe was calibrated to within $\pm 0.1^{\circ} \mathrm{C}$, over a temperature range of

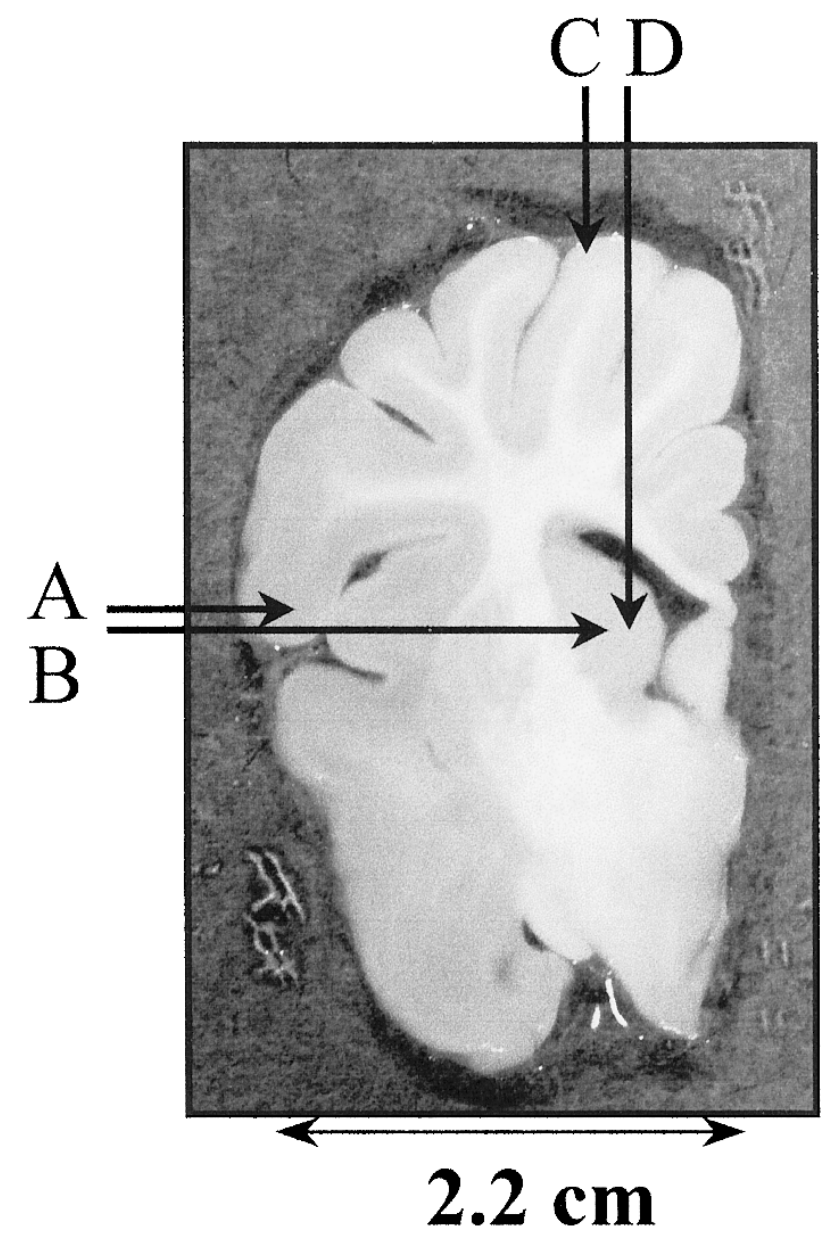

Fig. 1. Photograph of a coronal slice through one hemisphere of the newborn piglet brain marking the position of the four brain temperature sensors $A(0.2$ $\mathrm{cm}$ into cortex), B (1.7 cm into deep gray matter), C (epidural), and D (2 cm into deep gray matter).

$20-40^{\circ} \mathrm{C}$, against a certified mercury in glass thermometer (Zeal, London, U.K.). The rectal, skin, fontanelle, epidural, and type D deep brain probes were connected to an Olympic Medical Cool Care System (Seattle, WA, U.S.A.) SHC device, which recorded and stored temperatures at 1-min intervals. All physiologic variables were recorded manually at 10 -min intervals, and continuously onto a chart recorder (Gould Instrument Systems, Ilford, Essex, U.K.) throughout the experiment.

Normal piglet core temperature $\left(39^{\circ} \mathrm{C}\right)$ was maintained by an overhead radiant heater (Fisher \& Paykel Infant Warmer, Aukland, New Zealand) positioned $80 \mathrm{~cm}$ above the piglet and giving $30 \%$ (median) of maximum output, providing an ambient cot temperature of $28^{\circ} \mathrm{C}$ (range, $27-30^{\circ} \mathrm{C}$ ). During SHC, $100 \%$ overhead heating was commenced when the rectal temperature reached $35^{\circ} \mathrm{C}$, raising the ambient cot temperature to a median of $32^{\circ} \mathrm{C}$ (range $30-35^{\circ} \mathrm{C}$ ). A reflective insulating shield (Olympic Medical) was placed over the piglet head to ensure that the overhead heater warmed only the exposed body below the neck.

EEG monitoring. Single-channel parietal EEG was recorded during the insult and cooling-rewarming periods (Oxford Medilog 9000, Oxford Medical Systems Ltd, Oxford, U.K.). 
Table 1. Temperature values during cooling and rewarming

\begin{tabular}{|c|c|c|c|}
\hline \multirow[b]{2}{*}{ Period } & \multicolumn{2}{|c|}{ Group A $(n=4)$} & \multirow{2}{*}{$\begin{array}{c}\begin{array}{c}\text { Group B } \\
(\mathrm{n}=4)\end{array} \\
\text { Postinsult cooling }\end{array}$} \\
\hline & Preinsult cooling & Postinsult cooling & \\
\hline Lowest T-rectal $\left({ }^{\circ} \mathrm{C}\right)$ & $33.7(32.8-34.7)$ & $33.5(33-35.2)$ & $33.8(33-34.7)$ \\
\hline Lowest T-deep brain $\left({ }^{\circ} \mathrm{C}\right)$ & $28.5(24.3-30.3)$ & $30.6(25.6-33.2)$ & $29.5(24.2-32.3)$ \\
\hline T-rectal - T-deep brain gradient $\left({ }^{\circ} \mathrm{C}\right)$ & $5.3(4.2-8.5)$ & $3.0 *(1.7-7.4)$ & $4.3(2.4-8.8)$ \\
\hline $\begin{array}{l}\text { T-rectal }-\mathrm{T} \text {-deep brain gradient when T-rectal } \\
\text { reached } 39^{\circ} \mathrm{C}\end{array}$ & $4.3(2.7-8.0)$ & $4.5(3.5-4.7)$ & $4.9(2.5-6.5)$ \\
\hline
\end{tabular}

Values are median (range). ${ }^{*}$ Different $(p \leq 0.05)$ results after hypoxia-ischemia.

Head cooling cap. A custom made cooling cap with a network of circulating water channels (Cool Care System, Olympic Medical) was obtained for this study. It was fitted around the head and snout, avoiding contact with the neck. A disposable diaper around the cap acted as an outer insulating layer. The temperature of the circulating water could be adjusted from 6 to $24^{\circ} \mathrm{C}$.

After insertion of the monitoring equipment, the piglet was placed in prone position and rested for a 60 -min stabilizing period. Group A $(n=4)$ then underwent preinsult coolingrewarming, followed by the insult then postinsult coolingrewarming. Group B $(n=4)$ proceeded directly to the insult followed by postinsult cooling-rewarming. Cooling was induced by the circulation of cooled water through the cap, initially at $6^{\circ} \mathrm{C}$, with no overhead heating. When the T-rectal fell to $35^{\circ} \mathrm{C}$, overhead heating was commenced at $100 \%$. A steady-state was then achieved by adjusting the cap temperature to that which allowed the maximal overhead heating to maintain a stable T-rectal. The median cap temperature that stabilized T-rectal and T-deep brain was $10^{\circ} \mathrm{C}$ (range, $6-16^{\circ} \mathrm{C}$ ). After $20 \mathrm{~min}$ of temperature equilibration, rewarming was started with $2-6^{\circ} \mathrm{C}$ increments in cap temperature, with stabilization at each increase, until $24^{\circ} \mathrm{C}$ (the maximum cap set temperature) was reached. The water flow was then switched off, with the water-filled cap left in situ. Warming with the overhead heater was continued until T-rectal was $39^{\circ} \mathrm{C}$. A ninth piglet followed the same protocol as group A, but the overhead heater was not turned on until T-rectal had fallen to $31^{\circ} \mathrm{C}$.

Acute cerebral HI. The inspired oxygen concentration was lowered abruptly to 4 to $6 \%$ to reduce the real-time EEG record to a background amplitude of $<7 \mu \mathrm{V}$. The insult was terminated after $45 \mathrm{~min}$, and the piglet was resuscitated with an increased inspired oxygen concentration until the transcutaneous arterial oxygen saturation was maintained at $\geq 96 \%$.

Histopathology. The brains were perfusion fixed as previously reported (16). The position of the temperature probes was verified from 6- $\mu \mathrm{m}$ serial sections, an example of which is shown in Figure 1. There were no gross hemorrhages caused by probe insertion.

Data analysis. For comparisons of discrete variables within and between groups, $t$ test (paired or unpaired) was used for parametric and Mann-Whitney $U$ test for nonparametric data.

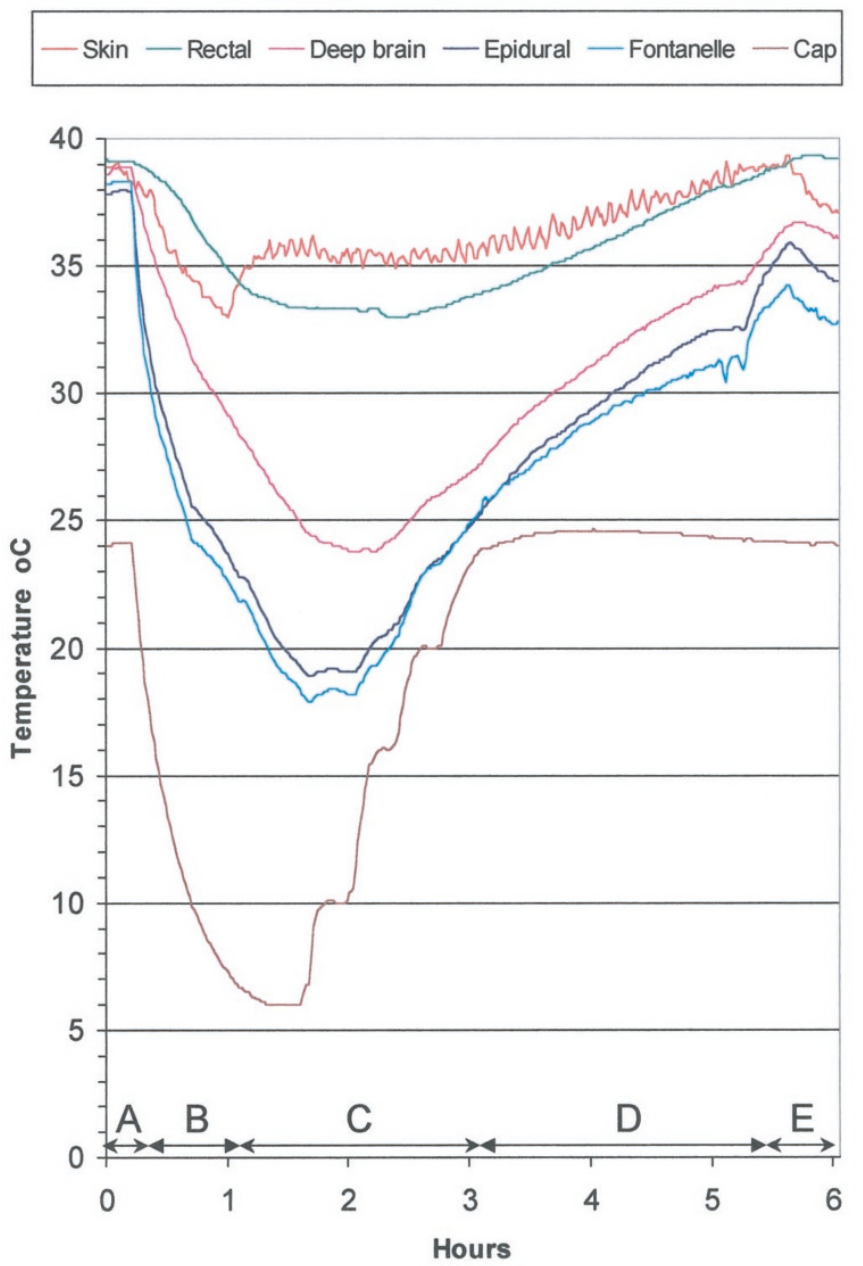

Fig. 2. Temperatures recorded at 1-min intervals from skin, rectum, deep brain (probe D, Fig. 1), epidural space (probe C, Fig. 1), fontanelle, and water in the cap for a piglet that was cooled only after the insult (group B). The figure demonstrates that a stable T-deep brain to T-rectal gradient is achieved by increasing the skin temperature using the overhead heater and lowering brain temperature by reducing the temperature of water in the cap. Time period A represents baseline with a small amount of overhead heating to maintain normal T-rectal. Period B is when the overhead heater is off, and the cooling cap is set to $6^{\circ} \mathrm{C}$. In period $\mathrm{C}$, the overhead heater is maximal, and cold water is circulated through the cooling cap at increasing temperatures to determine the cap temperature that balances full overhead heating at a stable T-rectal. During period D, the overhead heater remains on full, but the circulation in the cap is stopped with the cap left in situ. Period E is when the overhead heater is turned down to maintain normal T-rectal. 
A probability value $<0.05$ was considered significant (two-tailed).

\section{RESULTS}

The nine piglets used had a median age of $7.5 \mathrm{~h}$ (range, 3-24 h), with a median weight of $1485 \mathrm{~g}$ (range, $1180-1760 \mathrm{~g}$ ).

During head cooling and body warming, it was possible to cool the brain more than the body, and create a T-rectal to T-deep brain gradient in all animals both before (group A) and after (groups A and B) hypoxia (Table 1). This gradient was significantly smaller after the hypoxic insult; the median peak gradient during cooling before hypoxia was $5.3^{\circ} \mathrm{C}$, and after the hypoxic insult, $3.0^{\circ} \mathrm{C}$. When the T-rectal to T-deep brain gradient was at its largest during cooling, there was also a marked skin to rectal gradient in all pigs, the skin being warmer than T-rectal by a median of $2.5^{\circ} \mathrm{C}$ (range, $1.7-3.5^{\circ} \mathrm{C}$ ). Figure 2 illustrates changes in temperature during cooling and rewarming after an $\mathrm{HI}$ insult in one piglet from group $\mathrm{B}$. The T-rectal to T-brain gradient was created when the overhead

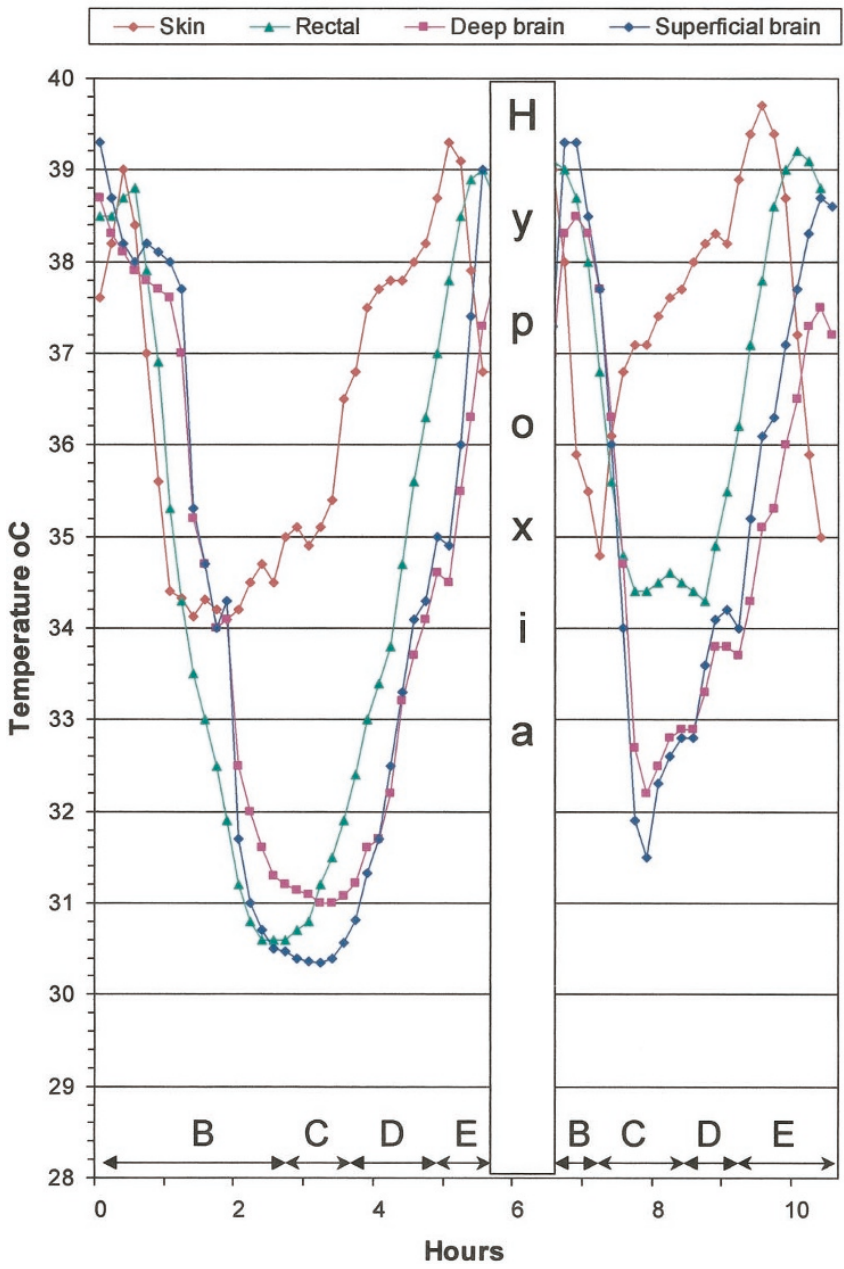

Fig. 3. The importance of the overhead heater in creating a T-rectal to T-deep brain gradient is shown. In this pig, at the start of the experiment the overhead heater was off and the cooling cap was set to $6^{\circ} \mathrm{C}$, but the overhead heater was not commenced when T-rectal reached $35^{\circ} \mathrm{C}$ (as it was in the other pigs). The graph shows that T-rectal fell in parallel with brain temperature until full overhead heating was commenced at rectal temperature of $31^{\circ} \mathrm{C}$, and it was only at this point that a T-rectal to T-deep brain gradient was created.

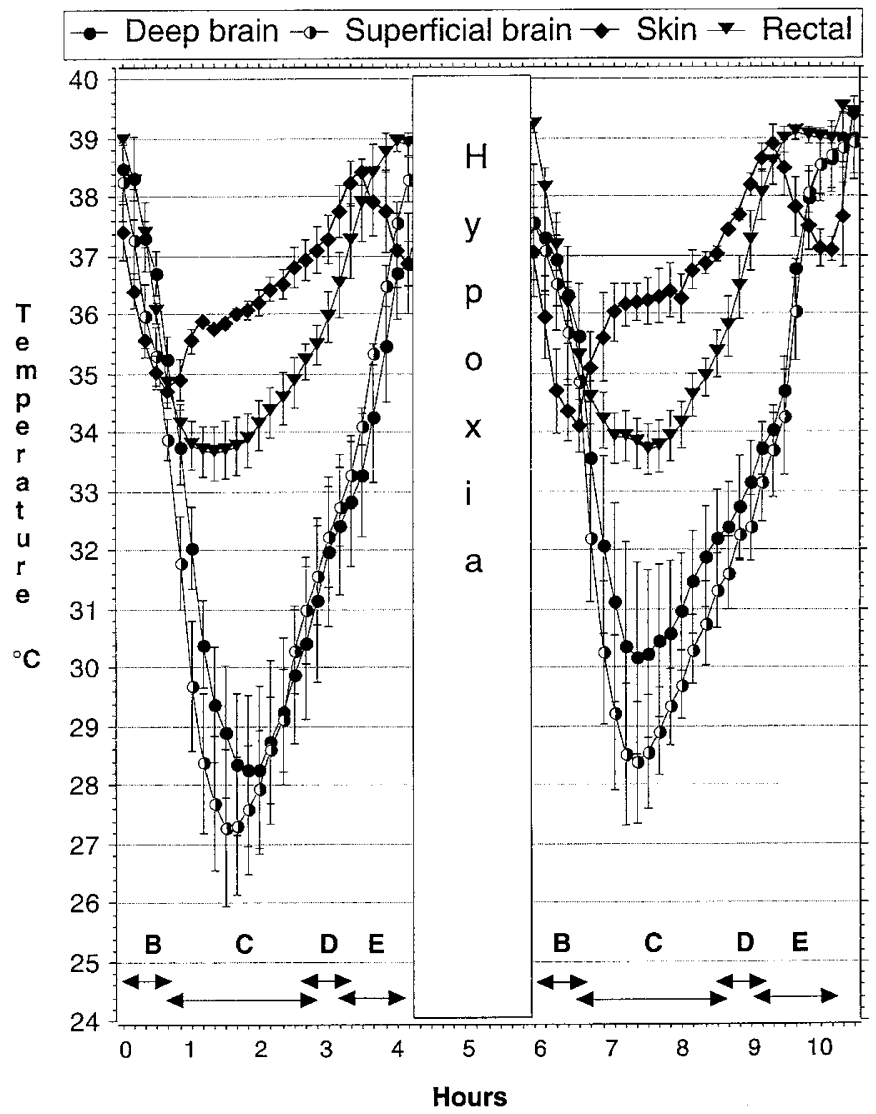

Fig. 4. Changes in temperature (mean \pm SEM) of skin, rectum, superficial (probe A), and deep brain (probe B) during cooling and rewarming before and after the hypoxic insult in four pigs from group A. Labels B-E on the $x$ axis are defined as in Figure 2.

heater was turned on. The cooling cap temperature was increased in steps from $6^{\circ} \mathrm{C}$ to the temperature that stabilized T-rectal when the overhead heater was set at $100 \%$. Figure 3 shows how a T-deep brain to T-rectal gradient was accomplished with the use of overhead heating. During cooling before the insult, the overhead heater was first set to $100 \%$ output when the T-rectal had fallen to $31^{\circ} \mathrm{C}$, and the T-deep brain was $32^{\circ} \mathrm{C}$ (labeled B). Head cooling without overhead heating simply cooled the whole animal. During cooling after the insult, the overhead heater was turned on when T-rectal reached $35^{\circ} \mathrm{C}$, and a T-rectal to T-deep brain gradient of $2^{\circ} \mathrm{C}$ was obtained (labeled C). D was when the cap temperature was increased to $24^{\circ} \mathrm{C}$, and the flow in the cap was stopped. Figure 4 shows the mean temperature changes for the four piglets in group A (cooled and rewarmed both before and after the HI insult). Two cooling-rewarming periods are shown, the second starting directly after the end of the hypoxic insult. The Trectal to T-deep brain gradient was reduced after the $\mathrm{H} 1$ insult (Table 1). Table 2 shows the cardiovascular measurements during the cooling-rewarming periods. There was no significant difference in any variable between groups A and B during cooling after hypoxia, although group B had more severe insults (by chance) and tended to be more compromised as shown by lower blood pressure, $\mathrm{pH}$, and base excess values after hypoxia. 
Table 2. Physiologic variables for cooling before and after hypoxia-ischemia (group A) or only after hypoxia (group B)

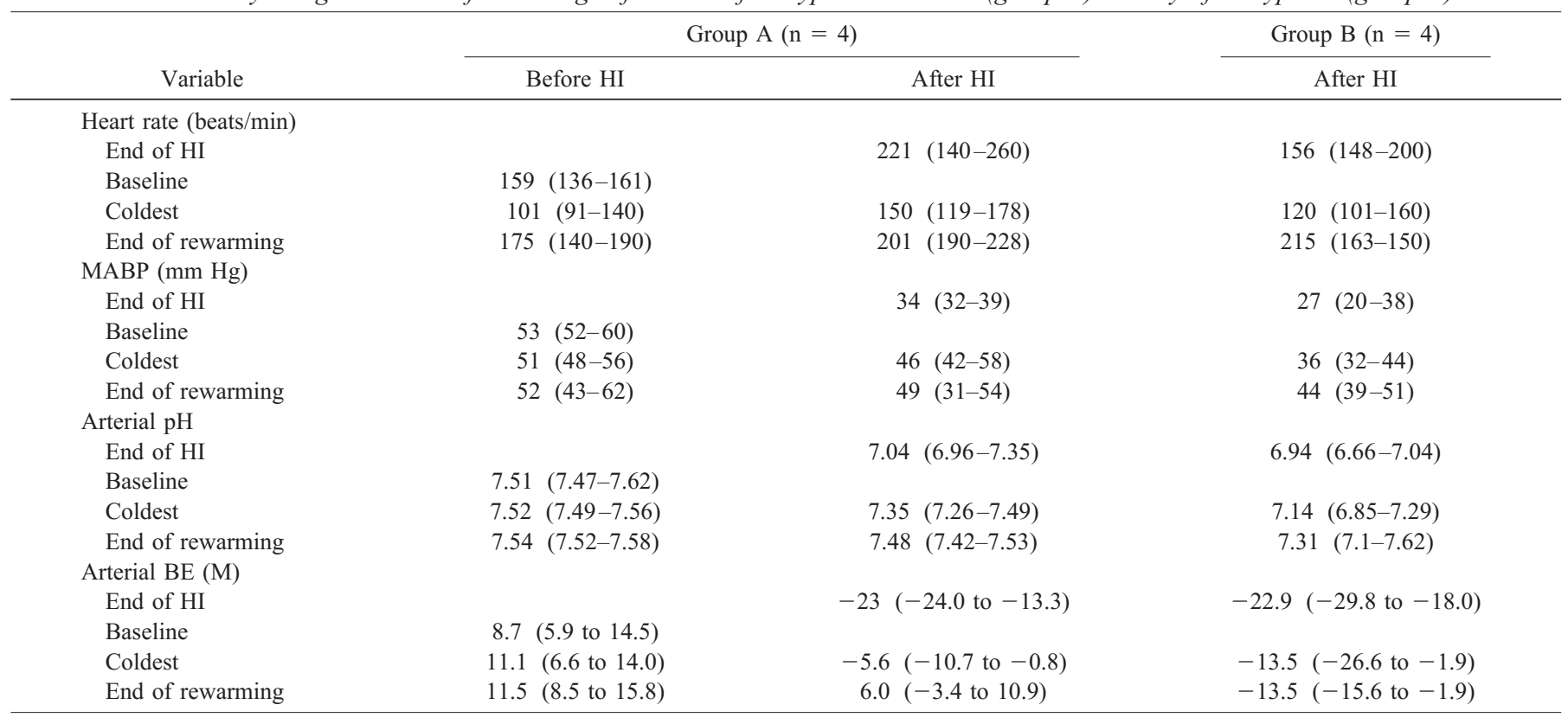

Values are median (range).

Abbreviations: HI, hypoxia-ischemia; BE, base excess.

\section{DISCUSSION}

We demonstrate for the first time by direct measurement of intracerebral temperatures that a cap circulated with cold water is an effective method of selective brain cooling in piglets. This study shows that it is possible to cool the brain more than the body and, by using a combination of overhead heating and a head cooling cap, to create a substantial T-rectal to T-deep brain gradient. An overhead body heater is essential in the creation of the T-rectal to T-deep brain gradient, and head cooling without overhead heating leads to total body cooling. The skin of the trunk has to be warmer than core (deep rectal) for the brain to be colder than core.

In adults, the temperature of the brain is higher than that in the core by $0.5^{\circ} \mathrm{C}$, and there are temperature gradients within the brain. In a magnetic resonance spectroscopy study on healthy human adults, the thalamus was $37.7^{\circ} \mathrm{C}$ and the frontal cortex was $37.2^{\circ} \mathrm{C}$ (18). In adult neurosurgical and stroke patients with brain injury, brain temperature was $1-3^{\circ} \mathrm{C}$ higher than core temperature $(13,19)$. Although similar measurements are not available for newborn human babies, SHC may not only be potentially useful in the prevention or reduction of systemic side effects, but also in the prevention of selective deep brain hyperthermia after an $\mathrm{HI}$ insult.

Our direct measurements of brain temperature in this paper do not support the recently published mathematical heat exchange model of SHC in the newborn human baby (14). There are, of course, differences between the pig and the human baby. The newborn piglet weighs around $1.6 \mathrm{~kg}$ and the newborn human $3.2 \mathrm{~kg}$; the piglet brain comprises $2.3 \%$ of total body weight (20) and is only $4.5 \mathrm{~cm}$ in coronal width, whereas in the human newborn the brain comprises $15 \%$ of body weight. The piglet cooling cap covered $100 \%$ of all available head surface area (including the face and snout but not the ears and neck), but in the human newborn the cap specifically avoids the face and forehead (which represent $45 \%$ of the total head surface area). On the other hand, it may be easier to cool the brains of newborn infants selectively because of the presence of the anterior and posterior fontanelles and an ability to lose heat from the upper airway during respiration (21). There are heat exchangers in human babies, like the approximation of the carotid siphon to the cavernous sinus, the proximity of the carotids to the upper respiratory tract, and the vertebral arteries passing through the vertebral venous plexus. There are also functional peculiarities in the vasculature of the newborn head. In human babies vasoconstrictor reflexes are absent from the forehead, potentiating heat loss from the head (22). Moreover, the circulation of the pig brain differs from that of the human. The piglet has a rete caroticum (23), which is a multichanneled version of the human internal carotid artery. The rete is surrounded by the cavernous sinus, and this forms an effective heat exchange mechanism. It has been shown previously that the core and brain temperatures in nonrete animals (such as humans) are closer to each other than they are in rete animals (24), but we have found, however, during normothermia and total body hypothermia that T-deep brain and T-rectal were within $0.5^{\circ} \mathrm{C}$ of each other in the pig (17). Increased blood flow is expected to make it more difficult to maintain a gradient. Cerebral blood flow values are reported to be $40-60 \mathrm{~mL} / 100$ $\mathrm{g} / \mathrm{min}$ in the newborn piglet, which is slightly higher than in the human infant. The fact that we were able to create a T-rectal to T-deep brain gradient of up to $8^{\circ} \mathrm{C}$ in a species with high cerebral perfusion is very encouraging. One can speculate that it should be easier to cool a smaller and more immature brain with lower cerebral blood flow as in the premature baby compared with a large term infant.

In our study, the median rectal to deep brain gradient was significantly smaller after the insult $\left(3^{\circ} \mathrm{C}\right.$ versus $\left.5.3^{\circ} \mathrm{C}\right)$, which may reflect a transient period of early post-HI hyperperfusion. 
The period of cooling in this study was short because it was not the aim to maintain a gradient long term. However, it is possible to maintain a T-rectal to T-deep brain gradient of $>3^{\circ} \mathrm{C}$ for $24 \mathrm{~h}$ of hypothermia in this model (Thoresen $\mathrm{M}$, personal communication).

It is very encouraging that despite moderate to severe hypothermia of the brain surface, we have found no gross hemorrhages caused by probe insertion, or deranged coagulation.

Our results show that $\mathrm{SHC}$ is possible in a piglet model of global hypoxia. SHC allows the T-rectal to be kept at a significantly higher temperature than the brain, which could potentially reduce the side effects of systemic hypothermia and improve neuroprotection. Until it is feasible to measure T-deep brain safely and noninvasively in the human brain, we believe the newborn pig may be the closest approximation available to us. At present it is reasonable to expect that SHC is also effective in the term infant, although we do not know whether a temperature gradient can be maintained for the deepest parts of the brain.

Acknowledgments. The authors thank Olympic Medical (Seattle, WA, U.S.A.) for lending us the Cool Care System and to Masimo (San Diego, CA, U.S.A.) for the pulse oximeter.

\section{REFERENCES}

1. Thoresen M, Penrice J, Lorek A, Wyatt J, Cady EB, Wylezinska M, Kirkbridge V, Cooper C, Edwards D, Brown G, Reynolds EOR 1995 Mild hypothermia following severe transient hypoxia-ischaemia ameliorates delayed (secondary) cerebral energy failure in the newborn piglet. Pediatr Res 5:667-670

2. Thoresen M, Baagenholm R, Løberg EM, Apricena F, Kjellmer I 1996 Posthypoxic cooling of neonatal rats provides protection against brain injury. Arch Dis Child 74:F3-F9

3. Sirimanne ES, Blumberg RM, Bossano D, Gunnong M, Edwards AD, Gluckman PD, Williams CE 1996 The effect of prolonged modification of cerebral temperature on the outcome after hypoxic-ischaemic brain injury in the infant rat. Pediatr Res 39:591-597

4. Gunn AJ, Gunn TR, deHaan HH, Williams CE, Gluckman PD 1997 Dramatic neuronal rescue with prolonged selective head cooling after ischemia in fetal lambs. J Clin Invest 99:248-256
5. Haaland K, Løberg EM, Steen PA, Thoresen M 1997 Posthypoxic hypothermia in newborn piglets. Pediatr Res 41:505-512

6. Bona E, Løberg EM, Baagenholm R, Hagberg H, Thoresen M 1998 Protective effects of moderate hypothermia after hypoxia-ischaemia in a neonatal rat model: short and long term outcome. Pediatr Res 43:738-745

7. Rohrer MJ, Natale AM 1992 Effect of hypothermia on the coagulation cascade. Crit Care Med 20:1402-1405

8. Frank SM, Higgins MS, Fleisher LA, Sitzman JV, Raff H, Breslow MJ 1997 Adrenergic, respiratory and cardiovascular effects of core cooling in humans. Am J Physiol 272:R562-R577

9. Leonov Y, Sterz F, Safar P, Radovsky A, Oku K, Tisherman S, Stezoski SW 1990 Mild cerebral hypothermia during and after cardiac arrest improves neurologic outcome in dogs. J Cereb Blood Flow Metab 10:57-70

10. Gunn AJ, Gluckman PD, Gunn TR 1998 Selective head cooling in newborn infants after perinatal asphyxia: a safety study. Pediatrics 102:885-892

11. Thoresen M, Whitelaw A 2000 Cardiovascular changes during mild therapeutic hypothermia and rewarming in infants with hypoxic ischaemic encephalopathy. Pediatrics 106:92-99

12. Corbett R, Laptook AR 1998 Failure of localised head cooling to reduce the brain temperature in adult humans. Neuroreport 9:2721-2725

13. Mellergard P 1992 Changes in human intracerebral temperature in response to different methods of brain cooling. Neurosurgery 31:671-677

14. Van Leeuwen G, Hand J, Lagendijk J, Azzopardi D, Edwards D 2000 Numerical modelling of temperature distributions within the neonatal head. Pediatr Res 48:351356

15. Tadler S, Callaway C, Menegazzi J 1998 Noninvasive cerebral cooling in a swine model of cardiac arrest. Acad Emerg Med 5:25-30

16. Thoresen M, Haaland K, Løberg EM, Whitelaw A, Apricena F, Hankø E, Steen PA 1996 A piglet survival model of posthypoxic encephalopathy. Pediatr Res 40:738748

17. Haaland K, Steen PA, Thoresen M 1996 Cerebral, tympanic and colonic thermometry in the piglet. Reprod Fertil Dev 8:125-128

18. Corbett R, Laptook A, Weatherall P 1997 Noninvasive measurements of human brain temperature using volume-localized proton magnetic resonance spectroscopy. J Cereb Blood Flow Metab 17:363-369

19. Schwab S, Spranger M, Aschoff A, Steiner T, Hacke W 1997 Brain temperature monitoring and modulation in patients with severe MCA infarction. Neurology 48:762-767

20. Chuntananukook S, Naiborhu A, Setiabudi M, Sheng H, Huggins R 1976 Growth of the pig: patterns of changes in electrolytes, water, and protein. Growth Dev Aging 40:99-102

21. Cabanac M, Caputa M 1979 Natural selective cooling of the human brain: evidence of its occurrence and magnitude. J Physiol (Lond) 286:255-264

22. Hertzman A, Roth L 1942 The absence of vasoconstrictor reflexes in the forehead circulation: effects of cold. Am J Physiol 136:692-697

23. du Boulay GH, Lawton M, Wallis A 1998 The story of the internal carotid artery of mammals: from Galen to sudden infant death syndrome. Neuroradiology 40:697-703

24. Hayward JN, Baker MA 1968 The role of the cerebral arterial blood in the regulation of brain temperature in the monkey. Am J Physiol 215:389-403 